ESTUDIO REGONOGIDO EN SU VERSIÓN DE ENSAYO EN EL SEGUNDO PREMIO DE ARGHIVÍSTICA DEL ARGHIVO GENERAL DE LA NAGIÓN - 2016

\title{
El proceso de reparto de tierras comunales en Michoacán y su documentación (1827-1915)
}

The Process for the Distribution of Communal Lands in Michoacán and Its Documentation, (1827-1915)

\section{Alicia Venegas González}

Archivo General e Histórico del Poder Ejecutivo de Michoacán aicila_68@hotmail.com

Cómo citar este artículo: Alicia Venegas González, "El proceso de reparto de tierras comunales en Michoacán y su documentación (1827-1915)", en Legajos. Boletín del Archivo General de la Nación, núm. 16 (mayo-agosto 2018), pp. 101-126.

\section{Resumen}

Acreedor de una mención honorífica en la categoría de ensayo del Segundo Premio de Archivística "Archivo General de la Nación - México" 2016, y adecuado a la modalidad de artículo, el presente trabajo aborda un recuento histórico del reparto de tierras comunales en Michoacán, durante el siglo XIX y principios del XX, así como la descripción del acervo documental generado, correspondiente a la serie "hijuelas", que en su momento dio sustento a las gestiones de este proceso y en la actualidad son testimonio histórico que nutren investigaciones del tema en cuestión

Palabras clave: Michoacán, hijuelas, indígenas, bienes comunales

\section{Abstract}

Winner for honorable mention in the essay category from the Segundo Premio de Archivística (Second Archivist Award) at the "Archivo General de la Nación-México" in 2016, and edited into an article, this article takes up the historic record of the distribution of communal lands in Michoacán, during the 19th century and beginning of the 20th, as well as the description of the resulting documentary collection, corresponding to the series "Hijuelas", that in its time supported the negotiations behind this process and currently are historical testimonies that feed into investigations of the subject in question.

Keywords: Michoacán, hijuelas, indigenous, communal property 


\section{Preámbulo}

El presente escrito es parte del análisis archivístico realizado en la descripción de la serie documental hijuelas y aborda solo algunos de sus apartados. Inicia con el recuento histórico sobre el reparto de tierras comunales en Michoacán, a lo largo del siglo xix y principios del xx, basado principalmente en las leyes, decretos y demás disposiciones oficiales que sobre esta materia se emitieron en la entidad, lo que nos da un panorama oficial de esta temática, a la vez que permite delimitar cómo se efectuó, las instituciones y autoridades que intervinieron, así como las gestiones que dieron origen a los documentos en cuestión. Posteriormente, se presenta la descripción general de la serie hijuelas, la conformación de los expedientes del reparto de acuerdo con el principio de orden original, y de manera sintética, las fases, actividades, y documentos generados en este proceso.

\section{Antecedentes}

Las comunidades indígenas de Michoacán provienen de la civilización mesoamericana, portadora de maneras de entender el mundo y organizar la vida, forjada en lo que hoy es México a lo largo de un complejo proceso histórico. Con una cosmovisión propia, basada en la estrecha relación entre los hombres, la sociedad, el mundo natural y sobrenatural, que constituyen uno de los elementos fundamentales de su entidad cultural.

Los indígenas practicaban una economía autosuficiente, basada en la diversidad de cultivos, complementados con la recolección, caza, pesca, crianza de animales domésticos, así como con alguna forma de producción artesanal. El trabajo se aplicaba para obtener de la naturaleza estrictamente lo requerido para satisfacer las necesidades humanas, la relación hombre-naturaleza debía ser recíproca para estar en armonía con el cosmos. ${ }^{1}$

${ }^{1}$ Bonfil Batalla, México profundo, pp. 21-23, 55-59. 
En el primer siglo de la Época Colonial, las tierras de la Nueva España pertenecían legalmente a la Corona española; sin embargo, éstas fueron pasando a comunidades y manos particulares a través de diversas formas de transmisión de la propiedad, como las peticiones de Merced y diversas cédulas reales que regulaban los derechos de posesión.

Las mercedes eran otorgadas por el virrey, la audiencia, el cabildo y la superintendencia, pudiendo ser beneficiarios particulares o pueblos, prefiriéndose a los descubridores, antiguos pobladores y a sus descendientes.

De acuerdo con lo anterior, los pueblos existentes antes de la Conquista, demostraron su derecho de propiedad ancestral sobre sus tierras, con pinturas, testamentos o relatos de los ancianos; de esta forma, mediante un título primordial se les reconocía jurídicamente, la posesión y usufructo en forma colectiva de una extensión en ejidos, tierras de común repartimiento, propios y fundos legales de los pueblos. ${ }^{2}$

Hacia 1530, los pueblos de indios se reconocieron legalmente como asentamientos humanos, con un gobierno integrado por indígenas; los funcionarios principales eran el gobernador, el alcalde y el regidor; el primero de éstos, era responsable de la recolección del tributo, la administración de los bienes y de las tierras de comunidad, de representar legalmente al pueblo ante el gobierno virreinal y ante la iglesia, así como de asignar las parcelas de tierra agrícola a los habitantes del lugar. Además, los pueblos contaban con cajas de comunidad, edificios públicos, hospitales, casas comunales donde muchas veces funcionaba la escuela y, por supuesto, la iglesia y sus cofradías. ${ }^{3}$

Durante la Época Colonial, a través de normas impuestas por las autoridades españolas, las comunidades indígenas tuvieron cada vez más restricciones para llevar la administración de sus bienes, sometiéndolos con esto a la explotación y al despojo por parte de autoridades, así como de hacendados y arrendatarios españoles. Con el surgimiento del

${ }^{2}$ Bolio Ortiz, "Modalidades de tenencia de la tierra", pp. 32, 33 y 40.

${ }^{3}$ García Ávila, Las comunidades indígenas, pp. 50-57. 
movimiento independentista, los insurgentes retomaron la demanda de restituir las tierras a los comuneros; sin embargo, desde el principio de la vida independiente, el gobierno adoptó un modelo liberal, que planteó el reparto de la propiedad comunal. ${ }^{4}$

Este proyecto inició en nuestro país, a principios del siglo XIx, cobrando auge a mediados del mismo con las Leyes de Desamortización y extendiéndose hasta los primeros años del siglo xx.

Con base en la Constitución general de 1824, varios estados promulgaron sus constituciones, en este marco jurídico, se uniformaron las formas de gobierno local a través del establecimiento de ayuntamientos, quedando sin efecto la organización política de los pueblos indígenas y autoridades que existieron en la Época Colonial; para ello se proclamó la igualdad civil a los indígenas, otorgándoles los mismos derechos y prerrogativas de ley que a cualquier otro ciudadano. Así mismo, en algunas entidades se expidieron las primeras leyes de reparto de bienes comunales

\section{Reparto en Michoacán}

El primer impulso del reparto de bienes comunales en el estado estuvo a cargo del gobernador José Salgado, quien presentó, en 1825, al Congreso local una propuesta de reglamento, considerando el principio de justicia que les asistía a los naturales, por ser descendientes de los primeros habitantes de este hemisferio.

De igual manera, consideraba que las personas, al saberse dueñas de su propiedad mejorarían su producción, contribuyendo así al fomento de la agricultura que para entonces era la rama más importante de la economía, al mismo tiempo que aumentarían el erario público. Por cuestiones de tiempo, este proyecto de reparto se retomaría meses después por el Congreso Constitucional. ${ }^{5}$

\footnotetext{
${ }^{4}$ Gutiérrez, La cuestión agraria, p. 16.

${ }^{5}$ García Ávila, Las comunidades indígenas, pp. 338-339, 343.
} 
En Michoacán, el reparto de tierras comunales inició con la Ley del 18 de enero de 1827, en sus nueve artículos especificaba que el reparto se haría exclusivamente entre los descendientes de las familias primigenias, es decir, de quienes originalmente habitaron estos territorios.

Las tierras obtenidas del reparto no se podrían vender, hipotecar, empeñar o enajenar durante los cuatro años siguientes a su posesión y propiedad. Los gastos del repartimiento correrían por cuenta de cada comunidad. ${ }^{6}$

El Reglamento del 15 de febrero de 1828, en sus 37 artículos, contenía las normas y el procedimiento para verificación del reparto de tierras. Entre otras disposiciones, señalaba que cada pueblo elegiría una comisión repartidora en reunión convocada por el prefecto de su distrito. Ésta formaría un padrón exacto de las familias que tuvieran derecho al reparto, así como una lista de las tierras consideradas para ese fin, incluyendo las propiedades que la comunidad tuviera en litigio.

La repartición se llevaría de la siguiente manera: para saber cuánto le correspondía a cada quien de manera equitativa, la comisión realizaría el avalúo de todas y cada una de las tierras a repartir, sumándolas después para obtener el valor total; el resultado lo dividiría entre el número de familias con derecho; sabido lo anterior, se procedería a las adjudicaciones, que era asignar a cada accionista en terreno, en dinero o en ambos, lo que le correspondía. Concluida la partición se daría posesión de los terrenos repartidos, señalando sus límites y linderos. El plazo para concluir el reparto no debía sobrepasar los 60 días. $^{7}$

La política de reparto en ese momento no tuvo éxito, pues el país atravesaba por una etapa de inestabilidad; por su parte, la legislación fue muy general y no contempló situaciones particulares que se presentaban cotidianamente; por otro lado, los indígenas no consideraban

${ }^{6}$ Coromina, Recopilación de leyes y decretos, t. II, pp. 61-62.

7 Coromina, Recopilación de leyes y decretos, t. III, pp. 29-35. 
necesario un cambio en la propiedad comunal, ya que en ésta se sustentaba la economía familiar, así como su organización colectiva, permitiendo dar continuidad a sus costumbres y tradiciones. El reparto era un proyecto ajeno a ellos, en el que no se les tomó en cuenta, quedando excluida su forma de pensar, de ver y de relacionarse con el mundo.

En teoría, esta ley se aplicaría fácilmente; sin embargo, en la práctica fueron apareciendo una serie de dificultades que la entorpecieron, como la falta de claridad sobre los derechos al reparto provocada por la mezcla de familias de unos pueblos con otros y la variación de residencia; la ausencia de títulos de los pueblos, la ignorancia y la percepción del gobierno en cuanto que había intereses particulares de algunos indígenas que por costumbre se aprovechaban de las tierras de todos. Ante estas dificultades, el gobierno amenazó a las comunidades con mandar tropa permanente para hacer el reparto, aunque en realidad no tenía la capacidad para hacerlo.

Otro elemento importante que impidió el reparto en esta primera etapa, fueron todos los movimientos políticos y militares que se vivieron durante más de veinticuatro meses en el ámbito nacional, mismos que influyeron para que en marzo de 1830 José Salgado dejara el cargo de gobernador, quedando abandonado el proyecto de reparto. Fueron pocas las comunidades que lo practicaron bajo esta ley, subsistiendo mayoritariamente el régimen comunitario. ${ }^{8}$

En los últimos años de la década de los cuarenta hubo comunidades que se levantaron contra la política gubernamental, situación que cambió con la intervención militar norteamericana. Después de este suceso el gobierno estatal ajustó mecanismos legales y expidió la segunda ley agraria importante, en 1851, con la cual se pretendió salvar las limitaciones que tenía la anterior. ${ }^{9}$

${ }^{8}$ García Ávila, Las comunidades indígenas, pp. 360-361, 364.

${ }^{9}$ Gutiérrez, La cuestión agraria, p. 18. 
La Ley del 13 de diciembre de 1851, constaba de 39 artículos, y su reglamento de 32. Este instrumento jurídico, entre otras cosas, excluyó del reparto las tierras y solares destinados a alguna utilidad pública, los fundos legales y los ejidos de los pueblos. ${ }^{10}$

Tendrían derecho al reparto cada uno de los individuos de la comunidad, cualquiera que fuera su edad, sexo y estado, así como los descendientes de solo padre o madre indígenas. Gozarían el mismo derecho quienes fueran admitidos en la comunidad siempre que hubieran desempeñado por cinco años, aunque no continuos, las obligaciones que ésta les hubiera encomendado. Los indígenas avecindados en otro lugar pero sin el tiempo y requisitos allí designados, tendrían este derecho en el pueblo de su ascendencia.

$\mathrm{Al}$ igual que en la ley anterior, cada comunidad nombraría una comisión repartidora de tres personas, pero que supieran leer y escribir, la cual formaría el padrón de individuos que tenían derecho al reparto, así como el de las tierras a repartir, no incluyendo las fincas o terrenos destinados a escuelas, los cuales se entregarían a la junta de instrucción primaria, como tampoco se incluirían los terrenos que estuvieran en litigio, esperando el resultado del juicio. El mismo padrón expresaría, en caso de haber, las cantidades de dinero que existieran pertenecientes a la comunidad, de donde una vez sufragados los gastos, el resto se repartiría.

Además, se contempló la formación de una comisión de reclamos, compuesta de tres individuos, así como un defensor de ausentes; estos nombramientos se harían en reunión de cada comunidad presidida por el alcalde $1^{\circ}$ en un lapso no mayor de treinta días de publicada la Ley.

El alcalde $1^{\circ}$ formaría tantos expedientes cuantos fueran los pueblos a repartir, el expediente constaría de: un ejemplar de esta Ley, su remisión a cada pueblo, fecha de reunión, comparecencia y lista

\footnotetext{
${ }^{10}$ Para 1887, se incluyó en el reparto el fundo legal de los pueblos en la parte que no estuviera ocupada con calles, plazas, panteones y edificios destinados al uso público. Véase Coromina, t. Xxix, p. 3.
} 
de asistentes, nombramiento del secretario, elección de los comisionados y defensores de ausentes, notificación a éstos y su aceptación, así como la de los suplentes, diligencias consiguientes al nombramiento y aceptación de los curadores que se nombraran y nota de haber dado parte a la prefectura, del estado que guardara cada expediente, éstos deberían entregarse al presidente de cada comisión.

Los padrones estarían concluidos en dos meses a partir de la fecha en que la comisión recibiera el expediente, y publicados por término de 15 días. A partir de entonces se otorgarían dos meses para reclamos por omisión de personas en el padrón, o sobre exclusión o inclusión de terrenos y su justiprecio.

Para proceder al reparto, se formaría la cuenta de partición entre todos los indígenas con derecho a ella, se dividirían los terrenos, procurando la mayor igualdad en cantidad y calidad, dejando a cada pueblo las 600 varas de fundo que exigía la real orden del 12 de julio de 1695, que debían medirse desde el centro de la iglesia por cada viento. Enseguida, la junta procedería a hacer las adjudicaciones y fijar el resultado en el lugar público más a propósito para el conocimiento de los interesados.

El importe de los gastos se cubriría por la comunidad. Las fincas repartidas, antes de cuatro años de la posesión no se podrían vender, hipotecar ni enajenar de ninguna manera, exceptuándose las pertenecientes a indígenas de ambos sexos, mayores de sesenta años sin hijos legítimos, los cuales, si quisieren su haber en dinero, se les daría en donde lo hubiera.

Esta Ley estipuló un año para la conclusión del reparto, quien no la acatara sería multado, quienes cumplieran se les exentaría del pago de contribuciones por 10 años. ${ }^{11}$ Aunque no en el tiempo establecido, pero bajo esta Ley se realizaron la mayoría de los repartos en Michoacán.

El 25 de junio de 1856, el Gobierno Federal decretó la Ley de Desamortización, en la que se ordenaba que todos los bienes poseídos

${ }^{11}$ Coromina, Recopilación de leyes y decretos, t. XI, pp. 195-205. 
o administrados por corporaciones eclesiásticas o civiles fueran adjudicados a sus inquilinos, o bien a quienes los denunciaran.

En Michoacán, los dirigentes políticos consideraron que esa Ley entorpecería los avances del reparto, por lo que el 20 de octubre del mismo año, el gobernador solicitó al presidente de la República que las propiedades de los pueblos indígenas de Michoacán se exceptuaran de lo dispuesto en dicha Ley, pero la respuesta fue negativa, señalando el plazo de tres meses para que se concluyera el reparto. ${ }^{12}$

Durante la intervención francesa, las comunidades tuvieron una relativa tranquilidad, ya que durante ese corto periodo Maximiliano reconoció el derecho a la posesión de las tierras comunales y a su organización comunal, calma que terminó con la restauración de la República.

De frente a la crisis económica y política que se vivía al término de la Intervención Francesa, en Michoacán los primeros gobernantes de la República Restaurada tomaron medidas encaminadas a mantener la tranquilidad para propiciar el desarrollo económico con las inversiones extranjeras y nacionales.

En el afán de ciudadanizar a los indígenas, así como de evitar brotes de violencia se dirigió la Circular de marzo 7 de 1868 a las prefecturas, indicando que no se vejara en nada a la clase indígena y se le guardaran así, tanto por las prefecturas como por las demás autoridades y funcionarios del departamento de su cargo, todas las garantías y preeminencias que las citadas leyes concedían a los ciudadanos libres del país. Pues el gobierno tenía conocimiento de que en algunos lugares no lo hacían, dándoles malos tratos y haciéndoles reportar cargas indebidas. ${ }^{13}$

El 9 de diciembre de 1868, de nueva cuenta se facultó al Ejecutivo estatal, de manera extraordinaria por el término de un año, para acelerar el reparto de los terrenos comunales, esta vez sin sujetarse a las formalidades establecidas por la Ley de la materia, pero observando

${ }^{12}$ Coromina, Recopilación de leyes y decretos, t. XIx, pp. 164-166.

${ }^{13}$ Coromina, Recopilación de leyes y decretos, t. XIX, pp. 42-43. 
los principios de justicia consignados en ella; esto último se refería a que el gobernador tendría cierta libertad de actuar en él, cómo efectuar el reparto, pero sin violentar los derechos de los indígenas.

Se le autorizó, igualmente, para que según las circunstancias concediera a las comunidades que lo solicitaran un término prudente para que haciendo por sí mismas y con entera libertad el reparto de los bienes que poseían en común, gozaran de la excepción de contribuciones. Dicho término no excedería de nueve meses contados desde la publicación de este decreto. ${ }^{14}$

A partir de 1869, el gobierno estatal impulsó, por todos los medios a su alcance, la desintegración de las comunidades, continuó con la política agraria de fraccionar y privatizar los terrenos comunales, nombró las respectivas comisiones repartidoras integradas, la mayoría de las veces, por funcionarios locales de cada pueblo, quienes no se ajustaban a la normatividad para tal efecto. Esa política gubernamental trajo altas dosis de fraudes, engaños y rapiña de las comisiones repartidoras y fue el factor más importante que desencadenó la violencia campesina, siendo duramente reprimida, pues el gobernador ordenó que en caso de detectarse acciones de descontento, se les sometiera por la fuerza. ${ }^{15}$

Para 1873 , la inestabilidad política se recrudeció a raíz de que las Leyes de Reforma fueron elevadas a rango constitucional por el presidente Lerdo de Tejada; surgió un grupo de inconformes a los que se les llamó religioneros y que alteraron el orden público; dos años después, intervinieron las fuerzas federales para sofocar estos levantamientos. Como respuesta, los rebeldes promulgaron el Plan de Urecho, donde proponían la derogación de la Constitución de 1857 y desconocían a Sebastián Lerdo de Tejada como presidente, ante lo cual, este último tomó medidas para calmar los ánimos. ${ }^{16}$

\footnotetext{
${ }^{14}$ Coromina, Recopilación de leyes y decretos, t. XIX, pp. 158.

${ }^{15}$ Sánchez Díaz, "Tenencia de la tierra, agricultura y ganadería", p. 233.

${ }^{16}$ Estrada Virgen, Reparto de tierras comunales, p. 11.
} 
El ascenso de Porfirio Díaz al poder inauguró una nueva etapa en el desarrollo económico y social, impulsó las inversiones extranjeras que penetraron en industrias como la petrolera, la eléctrica, la ferroviaria, la producción minera, así como en las actividades agrícolas. Otro aspecto fue la consolidación de una burguesía entreguista a los intereses imperialistas, la mayoría de sus miembros fueron importantes funcionarios públicos.

Respecto a la propiedad comunal, Díaz dio seguimiento parcial a las leyes de desamortización favoreciendo a los terratenientes, ocasionando con ello, problemas de litigios entre comunidades y haciendas debido a despojos de tierras y aguas. Por lo anterior, el gobierno tuvo que enfrentar diversos levantamientos campesinos, además de la negativa de los comuneros al reparto individual de sus terrenos.

En Michoacán los gobiernos porfiristas recibieron un buen número de compañías extranjeras, a las cuales apoyaron incondicionalmente, otorgándoles exenciones, estímulos fiscales y protección militar, lo que les permitió monopolizar las principales ramas productivas y recursos naturales como bancos de minas, bosques, tierras fértiles y agua.

Esta situación ocasionó numerosos actos de injusticia, como la usurpación y el despojo de tierras a comuneros y pequeños propietarios por los grandes hacendados con consentimiento de la autoridad, por lo que en 1879 varios indígenas recurrieron al presidente de la república, solicitando la expedición de una ley agraria que les hiciera justicia. En respuesta, se turnó el asunto al gobernador para que éstos fueran atendidos por las autoridades del mismo estado, instruyendo a su vez a los prefectos para que atendieran a los indígenas de su distrito y que estuvieran a la expectativa de alguna mira hostil o que tendiera a subvertir el orden público. ${ }^{17}$

Los indígenas ante sus problemas estaban solos, pues no podían obtener cobijo de las autoridades federales y estatales, ya que eran éstas quienes instrumentaban las políticas que los afectaban. Ante la negativa de parte de las autoridades de resolver las peticiones de los comuneros, éstos recurrían a la violencia como vía de defensa de sus derechos.

${ }^{17}$ Estrada Virgen, Reparto de tierras comunales, pp. 240-241. 
Diez años después, en 1889, la Secretaría de Fomento envió una circular al gobernador, indicando que para dar cumplimiento a la Constitución Federal en cuanto a que las corporaciones civiles no adquirieran o administraran por sí bienes raíces, se tuviera cuidado de que los pueblos no sufrieran perjuicio alguno a consecuencia de la supresión de los ejidos.

Así, las providencias dictadas con propósito de desintegrar la propiedad comunal, disponían que los terrenos a repartir, se convirtieran en un medio por el que los habitantes pobres de las poblaciones adquirieran gratuitamente una propiedad raíz con que pudieran subvenir a su subsistencia y procurarse un próspero porvenir; que para cumplir estos fines era necesaria la imparcialidad y pureza tanto en el fraccionamiento, la asignación de lotes y la entrega de títulos, evitando las preferencias arbitrarias y especulación, que según informes recibidos en dicha Secretaría, no pocas veces dejaban fuera del reparto o sin la porción que les correspondía a quienes tenían derecho.

Por lo anterior, el presidente de la república acordó que el gobernador dispusiera que en los actos de repartimiento y entrega de títulos de que se ha hecho mención, hubiera una eficaz vigilancia, concurriera a ellos la autoridad política de la jurisdicción a que correspondiera el pueblo de que se tratara, de modo que presidiera en todos esos actos la debida justicia, para obtener benéficos resultados y evitar toda clase de abusos. ${ }^{18}$

Es importante señalar que una cosa era lo que se plasmaba en las disposiciones oficiales y jurídicas, mientras que otra muy diferente el llevarlas a la práctica, pues se observa que continuamente eran violentadas o malinterpretadas, principalmente por autoridades y particulares que veían afectados sus intereses, incluso llegaba a suceder por parte de algunos comuneros.

El 14 de junio de 1902, se dictó una nueva Ley de reparto con un reglamento anexo. Ésta otorgó amplias facultades al Ejecutivo estatal, incluso para nombrar la comisión para el reparto sin consentimiento

${ }^{18}$ Coromina, Recopilación de leyes y decretos, t. xxx, pp. 17-18. 
de la comunidad, si ésta no lo hacía, así como para resolver los problemas de límites.

En sus 11 artículos convenía, entre otras cosas que: los ejidos, fundo legal, tierras y montes de los pueblos, se repartirían entre los vecinos de los mismos y no podrían ser enajenados, arrendados, hipotecados ni gravados en manera alguna sino con aprobación del gobierno y con las condiciones de ley.

Los terrenos del fundo legal y de los ejidos entretanto se fraccionaran y adjudicaran, serían administrados por los empleados de rentas respectivos, bajo la vigilancia de los ayuntamientos y las cantidades producidas por arrendamiento, censo, venta o cualquiera otra causa, ingresarían al erario municipal. ${ }^{19}$

El Reglamento se aprobó el 4 de julio de 1902, consta de 60 artículos distribuidos en tres capítulos y disposiciones generales, en los cuales estipulaba que cada comunidad debería nombrar a dos personas que practicaran las operaciones relativas al reparto, en caso de que éstas no tuvieran los conocimientos necesarios para hacer la medición, fraccionamiento y levantar el plano de las tierras repartibles, el gobierno podría nombrar a otra que lo hiciera en coordinación con los designados por la comunidad. Si dentro de un mes después de publicado este reglamento no hubieren propuesto la comisión de reparto, el gobierno la nombraría sin necesidad de acuerdo de los indígenas. El pago del reparto sería a cargo de ellos mismos.

Igual que en las leyes anteriores, la comisión formaría un padrón de las tierras que procederían al reparto, pero además elaboraría un plano o croquis para dar una idea exacta de la extensión y linderos de los terrenos que se dividirían. Las tierras a partirse se clasificarían en útiles para cualquier género de siembra, las puramente pastales, los terrenos de malpaís y los montes; listadas y clasificadas, la comisión procedería a medirlas y valuarlas.

Los manantiales que surtían de agua a las poblaciones o rancherías o que sirvieran de abrevadero de ganados, no se repartirían ni

${ }^{19}$ Coromina, Recopilación de leyes y decretos, t. XxxvI, pp. 510-512. 
tampoco los montes circundantes en una extensión de 90000 metros cuadrados, quedando dichos manantiales y montes al cuidado de los ayuntamientos respectivos.

Las aguas de regadío se repartirían en proporción a los lotes en que pudieran distribuirse, respetándose los usos establecidos, en cuanto no fueran contrarios a las leyes o a los principios de equidad y constituyéndose las servidumbres que natural y legalmente procedieran. A los ayuntamientos tocaría administrar las aguas que pertenecieran a los fundos legales y ejidos de los pueblos, arrendando los sobrantes.

Los terrenos repartidos no se podrían enajenar por espacio de cuatro años, sino con licencia del gobierno, y sus títulos serían extendidos por las prefecturas. El reparto se haría conforme a esta Ley, aun cuando llevaran el nombre de bienes de cofradías o estuvieran destinados a otros servicios que no fueran de interés procomunal. ${ }^{20}$

Como algunos representantes, sin autorización especial pretendían hacer enajenaciones, el gobierno recomendó a los notarios, abstenerse de autorizar escrituras de enajenación, arrendamiento, hipoteca o que gravaran de cualquier modo las tierras pertenecientes a las extinguidas comunidades, así como los ejidos, montes y fundo legal de los pueblos, pudiendo solamente hacerlo cuando el representante oficial presentara constancia escrita. ${ }^{21}$

Una buena disposición emitida por el gobierno, fue que en 1910 mandó establecer un espacio para el archivo generado por el proceso de reparto de bienes comunales; señalaba que por la frecuencia de casos en que representantes de los pueblos, extraviaban documentos importantes relativos a los intereses que representaban, por no tener un local apropiado para guardar el archivo a su cargo, conservaban esa documentación en sus casas particulares, en las que por incendio o descuido desaparecían papeles de suma importancia para los expresados indígenas.

${ }^{20}$ Coromina, Recopilación de leyes y decretos, t. XXXVI, pp. 515-533.

${ }^{21}$ Coromina, Recopilación de leyes y decretos, t. XXXVIII, pp. 292-293. 
En lo sucesivo, la mitad del local de oficinas destinadas a jefaturas, serían ocupadas por los representantes de cada lugar, para el despacho de sus asuntos. En ese espacio, se instalaría una mesa y una cómoda de 80 centímetros de lado fijada en la pared con su correspondiente candado, a fin de guardar en ella documentos relativos al cargo de los representantes y de esta manera quedaran seguros los documentos.

Además, los jefes de Tenencia vigilarían estrictamente que los representantes no sustrajeran ningún documento, lo cual sería sancionado, salvo aquellos casos en que por orden superior se tuviera que practicar alguna diligencia fuera de la oficina, o en la cual hubiera de intervenir alguno de los instrumentos que formaran el archivo; la llave del mismo debería estar en poder de los representantes, sin permitir que persona ajena al cargo manejara los papeles relativos a su cometido y los que estuvieran a su exclusivo cuidado. ${ }^{22}$

Las dos últimas administraciones porfiristas en Michoacán se caracterizaron por implementar una política de sangre y fuego, encaminada a la destrucción de las comunidades rurales mediante el reparto individual de las tierras comunales, el crecimiento de las propiedades privadas, la expansión de la agricultura comercial y la penetración en gran escala de los capitales extranjeros en diversas ramas de la economía michoacana, los empresarios del campo enfilaron su interés hacia los cultivos comerciales para la exportación, caña, arroz, café, tabaco, etcétera, desplazando los productos de la alimentación básica regional.

En el ámbito agrario se incrementó el proceso de reparto de las tierras de comunidad, lanzando a la miseria grandes masas campesinas. Así mismo, el gobierno reforzó la seguridad pública para asegurar la pacificación de la entidad, manteniendo el ambiente de confianza para la inversión extranjera y el resguardo de sus intereses, ante los malestares sociales que se vivían en la entidad como consecuencia de la política agraria y de la crisis que se extendía por todo México. ${ }^{23}$

${ }^{22}$ Coromina, Recopilación de leyes y decretos, t. XLI, pp. 15-16.

${ }^{23}$ Gutiérrez, La cuestión agraria, pp. 149-150. 
La permanencia de las comunidades en el estado, puso de manifiesto su capacidad para adecuarse y superar las medidas económicas del gobierno. De hecho ni por medios jurídicos o violentos pudieron desaparecer, pues a pesar de que se decretó su inexistencia jurídica, según disposición del 27 de septiembre de 1877, en que las comunidades indígenas organizadas conforme a las antiguas leyes españolas, no existirían más con ese carácter, éstas subsistieron.

La organización y concepción comunal no se perdió, siguió latente y permitió que al estallar la Revolución de 1910, se abriera la perspectiva de volver a plantear una nueva política agraria benéfica para los campesinos desposeídos. La fuerza armada permitió volver a plantear la existencia jurídica de las comunidades en Michoacán. Esta existencia real permite la regeneración de las comunidades a través de la restitución de la tierra, la conservación de las lenguas aborígenes, tradiciones, ética y organización comunal... ${ }^{24}$

El proceso de reparto tuvo una larga duración, casi un siglo, pese a que el gobierno desde un inicio estableció cortos periodos para su realización. Esta situación fue propiciada por varios motivos como lo fueron, la falta de convencimiento de muchas comunidades que estaban conscientes de que el reparto no solo destruiría la propiedad comunal, sino su organización social, forma de producción, productos de consumo, idioma, tradiciones, en general su cultura; los convertiría de dueños de la tierra en servidores de latifundistas.

Otros motivos fueron la inestabilidad política que atravesaba el país durante la primera mitad del siglo xIx, por las pugnas entre liberales y conservadores que planteaban sistemas de gobierno diferentes; las intervenciones estadounidense (1846-1847) y francesa (1862-1867); los actos de corrupción por parte de autoridades, terratenientes y de algunas

${ }^{24}$ Gutiérrez, La cuestión agraria, p. 24. 
comisiones repartidoras; así como los levantamientos que llevaron a cabo muchas comunidades ante los despojos e injusticias de que fueron víctimas.

Además, sobre todo en los dos primeros tercios del siglo xix, las vías de comunicación eran escasas y las disposiciones que sobre el reparto se emitían en la capital, tardaban en llegar a todos los rincones del estado, a su vez las dudas y planteamientos de las comunidades, tardaban en llegar al gobierno y lo mismo ocurría con la respuesta, aplazando a veces no solo meses, sino años, la resolución.

Otros elementos a considerar fueron el idioma, la falta de recursos para sufragar los gastos del reparto y el bajo nivel de escolaridad entre los comuneros, considerando que, para 1828, únicamente 37 pueblos indígenas contaban con centros de enseñanza de primeras letras, pues los comisionados para el reparto requerían de ciertos conocimientos o preparación ya que tenían que realizar trabajos como redacción de documentos, mediciones y operaciones matemáticas para el reparto, entre otras. ${ }^{25}$

\section{Descripción de la serie documental "Hijuelas"'26}

El reparto de bienes comunales en Michoacán, que comprendió desde principios del siglo xix, hasta principios del siglo xx, generó la documentación necesaria para dar seguimiento y sustento a dicho proceso, misma que actualmente se resguarda en el Archivo General e Histórico del Poder Ejecutivo de Michoacán y que a continuación se describe.

Este acervo quedó clasificado de la siguiente manera: Fondo: Secretaría de Gobierno; Sección: Gobernación; Serie: Hijuelas. Son libros organizados por distritos y éstos a su vez en orden alfabético, cabe mencionar que varios de éstos no cuentan con un estricto orden cronológico, alfabético, o geográfico en su interior; al parecer en la segunda mitad del siglo xx, se mandaron encuadernar los documentos sin cuidado de mantener su orden original.

${ }^{25}$ AGHPEM, Fondo: Secretaría de Gobierno, Sección: Gobernación, Serie: Memorias de Gobierno, 1828, ff. 16 a 18.

${ }^{26}$ Venegas González, "Expediente de reparto de bienes comunales”, p. 139-142. 
$\mathrm{Al}$ principio, estos documentos quedaron bajo la supervisión de la sección cuarta de la Secretaría de Gobierno, que era la oficina encargada de llevar el archivo de toda la institución; pero a partir de 1891, con el establecimiento del Archivo General y Público (hoy Archivo General e Histórico del Poder Ejecutivo de Michoacán), estos documentos pasaron a su custodia; los años que comprenden son de 1828 a 1915, se dividen en 16 distritos, con un total de 196 libros.

Son documentos originales, escritos en español en su mayoría con letra manuscrita y algunos mecanografiados; los tipos documentales que podemos encontrar son: actas de nombramiento de la comisión repartidora, padrones de los indígenas que tienen derecho al reparto y de los terrenos a repartir, peticiones varias, informes, respuestas del gobierno, comunicados, pagos de contribuciones; telegramas; certificaciones de propiedad; transcripciones certificadas de los títulos de propiedad comunal, recibos, información testimonial; además de firmas, diferentes tipos de sellos, timbres, croquis y planos.

Por contener valores histórico-legales, su conservación es permanente; se consulta para cuestiones legales de tierras, así como para investigaciones históricas que han dado como resultado ya varias publicaciones de temas vinculados con el reparto de tierras. ${ }^{27}$

El estado de conservación de esta serie no es uniforme, algunos libros están deteriorados por el paso natural del tiempo, pero otros se encuentran rotos, mutilados o manchados, por mal manejo, algunos han sido restaurados.

Para su consulta se pide utilizar guantes de látex o algodón y cubrebocas, además de las indicaciones generales del reglamento de

\footnotetext{
${ }^{27}$ Algunas de estas investigaciones son: De Estrada Virgen, "Reparto de tierras comunales y consolidación de la burguesía rural en Tancítaro, Los Reyes y Peribán (1867-1910)"; Pérez Escutia, "La política de desintegración de la propiedad comunal en la región oriente de Michoacán en el siglo XIX"; Sánchez Díaz, "Movimientos y rebeliones campesinas en el occidente de México en la segunda mitad del siglo XIX"; del mismo autor, "La comunidad nahua de Santiago Coalcomán. Reparto y resistencia en el s. XIx". Así como una de tipo archivístico titulada: "Expediente del reparto de bienes comunales en Tancítaro Michoacán” de mi autoría.
} 
consulta interno. Para apoyo de los usuarios se cuenta con un índice, que describe de manera general los expedientes que contiene cada libro, así como varios catálogos. Se autoriza la reproducción de este material si su estado de conservación lo permite, previa solicitud; para fines académicos, legales o culturales, se expiden copias certificadas.

Otras unidades de descripción que se relacionan temáticamente con las hijuelas y que se ubican en el mismo archivo son la recopilación de Leyes, Decretos, Reglamentos y Circulares expedidos en el estado de Michoacán, 1824-1915, las Memorias de Gobierno 1828-1904, y el Periódico Oficial.

\section{Guadro de clasificación de la serie hijuelas}

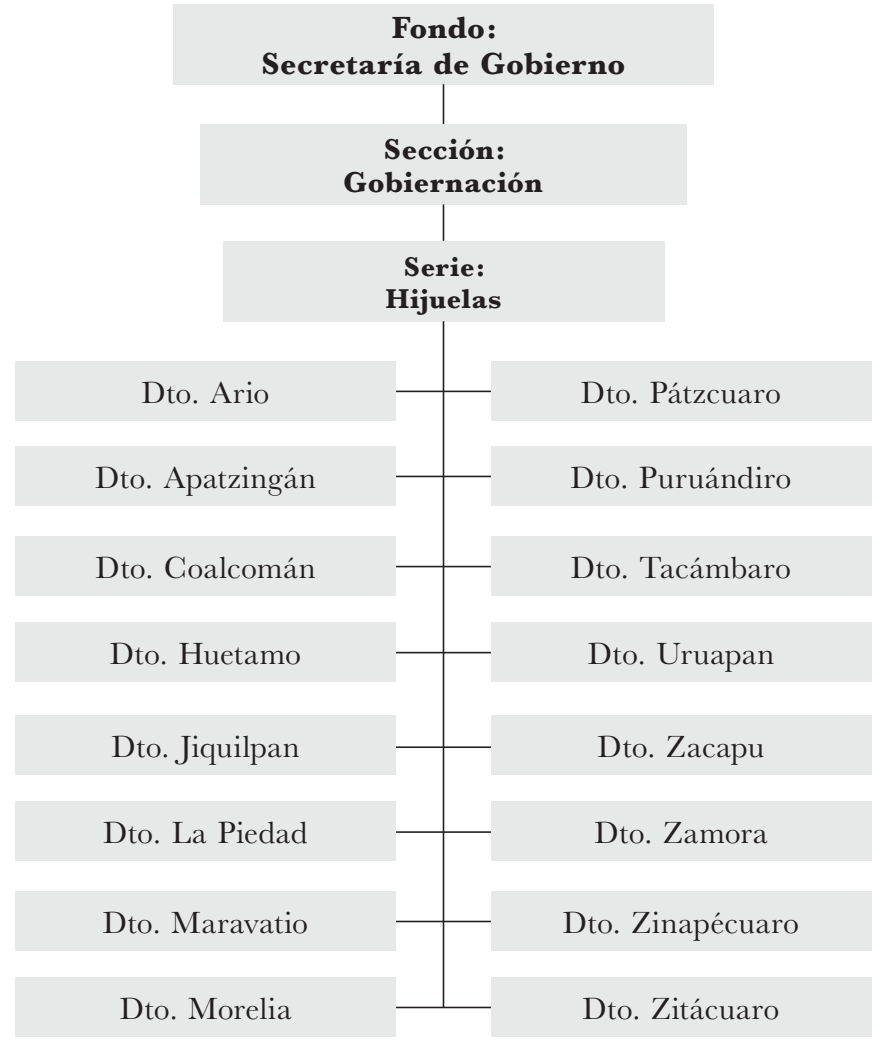




\section{Conformación de los expedientes de reparto de tierras comunales}

Normativamente debían constituirse de la siguiente manera:

El alcalde $1^{\circ}$ empezaría a formar los expedientes de los pueblos de su jurisdicción, en los que se llevaría el reparto, con los siguientes documentos:

1) Un ejemplar de la Ley.

2) La remisión de ésta a cada pueblo y la fecha de la reunión.

3) Lista de los que comparecieron.

4) Nombramiento del secretario.

5) La elección de los comisionados y defensores de ausentes.

6) Notificación a éstos y su aceptación, así como la de los suplentes, en caso de excusa de los propietarios.

7) Diligencias que son consiguientes al nombramiento y aceptación de los curadores que se nombraran.

8) Nota de haber dado parte a la prefectura, del estado en que se encuentre cada expediente.

Estos expedientes debían entregarse al presidente de cada comisión repartidora, dando recibo de él y notificando a la prefectura.

Ya en posesión de la comisión, ésta integraría los documentos que se fueran generando en lo sucesivo como son, las actas de sus reuniones, el padrón de individuos con derecho al reparto, el padrón de bienes a repartir, la cuenta de partición y adjudicaciones, los oficios de reclamos y resoluciones, remisión del expediente de reparto al gobierno para su aprobación, constancia de expedición de títulos de propiedad a los comuneros, así como toda la correspondencia entre los comuneros y autoridades relacionada con el reparto. 


\section{Circuito de tramitación y delimitación del proceso de reparto}

De acuerdo con sus atribuciones, el prefecto y el secretario de Gobierno podían resolver algunas cuestiones relativas al proceso de reparto de tierras, pero otras le competían exclusivamente al gobernador. El seguimiento de la tramitación del reparto de tierras era:

- El presidente de la comisión repartidora acudía al prefecto, quien a su vez enviaba el asunto al secretario de Gobierno, a través de la Oficialía $3^{\mathrm{a}}$ y éste lo turnaba al gobernador.

- La contestación vendría en la misma línea pero inversa.

De acuerdo con la Ley de 1851, el proceso de reparto de bienes comunales iniciaría con la publicación de la Ley, en febrero 29 de 1852, y un año después debería estar concluido. Este término solo podría prorrogarlo el gobierno por causa justa bien calificada.

\section{Fases del proceso}

\section{Inicio:}

- Publicación de la ley de reparto de bienes comunales.

- Tipo documental: Decreto o Ley.

\section{Desarrollo:}

- Reunión de la comunidad. - Tipo documental: Acta

- Nombramiento y notificación de las comisiones.

- Tipo documental: Nombramiento y notificación.

- Inicio de la formación del expediente de reparto. - Tipo documental: Expediente abierto

- Elaboración de los padrones de individuos y de terrenos a repartir.

- Tipo documental: Padrón, inventario 
- Publicación de los padrones

- Tipo documental: Cartel del padrón.

- Reclamos por omisión.

- Tipo documental: Solicitud, acta.

- Formación de la cuenta de partición y adjudicación de terrenos.

- Tipo documental: Cuenta de partición y adjudicación de terrenos.

- Publicación de la cuenta de partición de bienes y adjudicación.

- Tipo documental: Cartel de la cuenta de partición y adjudicación.

- Atención a los reclamos

- Tipos documentales: Solicitud, acta, resolución, informe.

- Enviar expediente de reparto al gobernador para su aprobación.

- Tipo documental: Oficio de remisión y expediente de reparto.

\section{Terminación:}

- Aprobación del reparto por el gobernador.

- Tipo documental: Acuerdo y comunicado

\section{Ejecución:}

- Expedición de títulos de propiedad

- Tipo documental: Título de propiedad o Certificado de hijuela 
Inventario general de los libros de hijuelas

\begin{tabular}{|c|c|c|}
\hline Distrito & Años & No. de libros \\
\hline Apatzingán & 1848-1907 & 9 \\
\hline Ario & $1833-1904$ & 6 \\
\hline Coalcomán & $1869-1907$ & 4 \\
\hline Huetamo & 1844-1912 & 9 \\
\hline Jiquilpan & 1830-1911 & 11 \\
\hline La Piedad & 1869-1906 & 7 \\
\hline Maravatio & 1869-1909 & 9 \\
\hline Morelia & $1828-1910$ & 38 \\
\hline Pátzcuaro & 1869-1910 & 21 \\
\hline Puruándiro & 1869-1911 & 4 \\
\hline Tacámbaro & 1848-1902 & 7 \\
\hline Uruapan & 1851-1929 & 21 \\
\hline Zacapu & 1828-1902 & 6 \\
\hline Zamora & 1832-1903 & 14 \\
\hline Zinapécuaro & $1828-1914$ & 21 \\
\hline Zitácuaro & 1828-1911 & 9 \\
\hline & & Total: 196 \\
\hline
\end{tabular}




\section{Conclusiones}

- En general: El reparto de tierras comunales fue parte del modelo liberal, adoptado en nuestro país en el siglo xix, que ocasionó explotación económica y opresión sociocultural de los indígenas.

- El reparto en Michoacán no fue homogéneo, en su mayoría se hizo de acuerdo a la Ley de 1851, aunque no en los tiempos estipulados jurídicamente. Además enfrentó problemas de diversa índole como conflictos al interior del grupo comunal, entre comunidades o con las autoridades, que en varias ocasiones desembocaron en la violencia.

- Los terrenos comunales fueron adquiridos por personas que contaban con el capital suficiente, como arrendatarios, empresarios agrícolas o funcionarios públicos, quienes desarrollaron una agricultura comercial y muchos indígenas se tuvieron que sumar como trabajadores asalariados, sometidos en muchos casos a condiciones infrahumanas de trabajo.

- Esta problemática fue retomada por el movimiento de 1910 y la Constitución de 1917 volvió a plantear la existencia jurídica de las comunidades.

- Los expedientes de reparto se conformaron en el orden original y lógico de la gestión de este proceso. Con el tiempo, por falta de políticas archivísticas claras se perdió ese orden original; sin embargo gracias a los trabajos de catalogación de esta serie documental, que retoman la norma ISAD (G), contribuyen a restablecerlo aunque en la fase de descripción, ya que físicamente no es conveniente por cuestiones de conservación. 


\section{Fuentes}

\section{Archivos}

AghPem Archivo General e Histórico del Poder Ejecutivo de Michoacán.

\section{Bibliografía}

Bolio Ortiz, Juan Pablo, "Modalidades de tenencia de la tierra en la Nueva España. Siglos xvi y xvı", en Revista Mexicana de Historia del Derecho, 1, 2013, pp. 29-40.

Bonfil Batalla, Guillermo, México profundo. Una civilización negada (Colección los noventa), México, Grijalvo-Conaculta, 1994.

Estrada Virgen, Elsa Dolores, "Reparto de tierras comunales y consolidación de la burguesía rural en Tancítaro, Los Reyes y Peribán (1867-1910)", tesis de licenciatura, umsnh-Escuela de Historia, Morelia, 2004.

García Ávila, Sergio, Las comunidades indígenas en Michoacán Un largo camino hacia la privatización de la Tierra, 1765-1835, Morelia, umsnhIIH, 2009.

Gutiérrez, Ángel et al., La cuestión agraria: Revolución y contrarrevolución en Michoacán (Tres ensayos), Morelia, umsnh, 1984.

Sánchez Díaz, Gerardo, "Movimientos y rebeliones campesinas en el occidente de México en la segunda mitad del siglo xIx", en Tzintzun. Revista de Estudios Históricos, núm. 12, 1990, pp. 45-77.

, "Tenencia de la tierra, agricultura y ganadería", Enrique Florescano (coord.), Historia General de Michoacán, vol. 
III, Morelia, Gobierno del Estado de Michoacán-IMc, 1989, pp. 232-250.

Reina, Leticia, "Ser indio o ser ciudadano", en Eslabones, núm. 6, 1993, p. 29.

Venegas González, Alicia, "Expediente del reparto de bienes comunales en Tancítaro, Michoacán”, en Legajos, núm. 7, 2015, pp. 125-154. 